\title{
Nion UltraSTEMTM: An Aberration-Corrected STEM for Imaging and Analysis
}

\author{
N.J. Bacon, G.J. Corbin, N. Dellby, P. Hrncirik, O.L. Krivanek, A. McManama-Smith, M.F. Murfitt, \\ and Z.S. Szilagyi \\ Nion Co., $11028^{\text {th }}$ St., Kirkland, WA 98033, USA \\ Adding a Nion spherical aberration $\left(\mathrm{C}_{\mathrm{s}}\right)$ corrector [1] to a Vacuum Generators (VG) scanning \\ transmission electron microscope (STEM) typically improves its resolution by $2-2.5 \mathrm{x}$, i.e. to better \\ than $1 \AA$ at $100 \mathrm{keV}$ [2] and to about $0.6 \AA$ at $300 \mathrm{kV}$ [3]. This has resulted in many new \\ applications for these instruments, such as numerous determinations of new structures, dynamic \\ studies, and single-atom-sensitivity EELS (e.g. [4]).
}

VG STEMs have several attributes that make such performance possible when retrofitted with an aberration corrector. The chief one is the high quality of their cold field emission guns (CFEGs), whose brightness is typically $>10^{9} \mathrm{~A} /\left(\mathrm{cm}^{2} \mathrm{sr}\right)$ at $100 \mathrm{kV}$. However, they also have weaknesses that create barriers to further progress. The VG condensers are difficult to align and drift for more than an hour if their current is changed. The objective lens in the $100 \mathrm{kV} \mathrm{VG}$ has a large upper bore, which prevents it from operating as a Riecke-type symmetric condenser-objective lens with minimized aberration parameters on both the entry and exit sides of the lens. Further, most $100 \mathrm{kV}$ VGs have no sample height (Z) adjustment capability, and have a weak post-sample objective lens field. This saddles them with varying optical parameters when the sample tilt is changed, and with poor post-sample compression and consequently a hard-to-optimize EELS collection efficiency.

Addressing these problems is essential for further progress, and this is the path now pursued at Nion. Accordingly, we are developing a new STEM column, and also a new $200 \mathrm{kV}$ cold field emission electron gun. The two projects presently proceed on separate tracks. New columns \#1 and \#2 are being assembled on top of existing $100 \mathrm{kV} \mathrm{VG}$ guns. They will be delivered in this configuration, with projected properties superior to any $100 \mathrm{kV} \mathrm{VG}$. The new gun is being developed in a separate lab. In the long run, the new column and the new CFEG will be combined in an instrument named Nion UltraSTEMTM.

The new column incorporates a new aberration corrector of fifth order aberration $\left(\mathrm{C}_{5}\right)$ in addition to $\mathrm{C}_{\mathrm{s}}$, described elsewhere in these proceedings [5]. It further has three condenser lenses (two round lenses plus a lens made from 3 quadrupoles) a symmetrical condenser-objective lens with $\mathrm{C}_{\mathrm{s}} \sim \mathrm{C}_{\mathrm{c}} \sim 0.8$ $\mathrm{mm}$, an ultra-stable 5-axis goniometer based on new construction principles, a detachable side-entry specimen cartridge that gives $+/-30^{\circ}$ of tilt in all directions, two post-specimen round lenses, a quadrupole lens module for EELS coupling, and a variety of detectors including bright-field, highangle and medium-angle dark-field detectors, a $1 \mathrm{k} \times 1 \mathrm{k}$ CCD camera for Ronchigram and general diffraction pattern recording, and a parallel detection EELS (Gatan Enfina). Theoretical HAADF resolution at $200 \mathrm{kV}$ is better than $0.4 \AA[5]$.

Table 1 compares the key properties of the new STEM with the VG STEM and a typical modern TEM/STEM column. Fig. 1 shows a mechanical drawing of the entire UltraSTEM ${ }^{\mathrm{TM}}$ including the new CFEG. Fig. 2 shows the new column being tested at Nion.

In summary, a new dedicated STEM with a $200 \mathrm{kV}$ CFEG, a C3/C5 aberration corrector, and several other new design elements is being developed at Nion. Results from its new electron-optical column will be presented at the meeting.

[1] N. Dellby et al., J. Electron Microscopy 50 (2001) 177.

[2] P.E. Batson, N. Dellby and O.L. Krivanek, Nature 418 (2002) 617.

[3] P.D. Nellist et al., Science 305 (2004) 1741. 
[4] O.L. Krivanek et al., Proceeedings 2004 MRS fall meeting, in press.

[5] N. Dellby et al., these proceedings.

\begin{tabular}{|c|c|c|c|}
\hline attribute & VG STEM & typical TEM/STEM & Nion UltraSTEM \\
\hline gun type & CFEG & Schottky & CFEG \\
\hline $\begin{array}{l}\text { gun brigtness at } 100 \mathrm{kV} \\
\left(\mathrm{A} /\left(\mathrm{cm}^{2} \mathrm{sr}\right)\right.\end{array}$ & $1 \times 10^{9}$ & $2 \times 10^{8}$ & $>1 \times 10^{9}$ \\
\hline vacuum sealing method & $\begin{array}{l}\text { single or double o- } \\
\text { rings (w. guard vac.) }\end{array}$ & single O-rings & $\begin{array}{l}\text { metal seals (except } \\
\text { for detectors) }\end{array}$ \\
\hline sample-level press. (torr) & $<10^{-8}$ to $<10^{-9}$ & $\sim 10^{-7}$ & $<10^{-9}$ \\
\hline column bake temp. $\left({ }^{\circ} \mathrm{C}\right)$ & $120-140$ & not bakeable or 80 & 120 \\
\hline objective lens (OL) type & $\begin{array}{l}\text { asymmetric (symm. at } \\
300 \mathrm{kV})\end{array}$ & $\begin{array}{l}\text { symmetric } \\
\text { condenser-objective }\end{array}$ & $\begin{array}{l}\text { symmetric } \\
\text { condenser-objective }\end{array}$ \\
\hline $\begin{array}{l}\text { typical OL aberration } \\
\text { coefficients }(\mathrm{mm})\end{array}$ & $\mathrm{C}_{\mathrm{s}}=1.3 \quad \mathrm{C}_{\mathrm{c}}=1.3$ & $\begin{array}{l}\mathrm{C}_{\mathrm{s}}=0.5-1.2 \quad \mathrm{C}_{\mathrm{c}}=1.2 \\
\text { (polepiece-dependent) }\end{array}$ & $\mathrm{C}_{\mathrm{s}}=0.8 \quad \mathrm{C}_{\mathrm{c}}=0.8$ \\
\hline $\begin{array}{l}\text { post-sample angular } \\
\text { compression }\end{array}$ & $\begin{array}{l}3 x(100 \mathrm{kV}) \\
5-10 x(300 \mathrm{kV})\end{array}$ & $50-100 x$ & $20-100 x$ \\
\hline sample holder & $\begin{array}{l}\text { cartridge: top insertion } \\
(100) \text {; side ins. }(300)\end{array}$ & side entry rod & $\begin{array}{l}\text { side insertion } \\
\text { cartridge }\end{array}$ \\
\hline sample Z-adjustment & no (100); yes $(300)$ & yes & yes \\
\hline
\end{tabular}

Table 1. Key parameters of the new column compared to VG STEMs and modern TEM/STEMs.

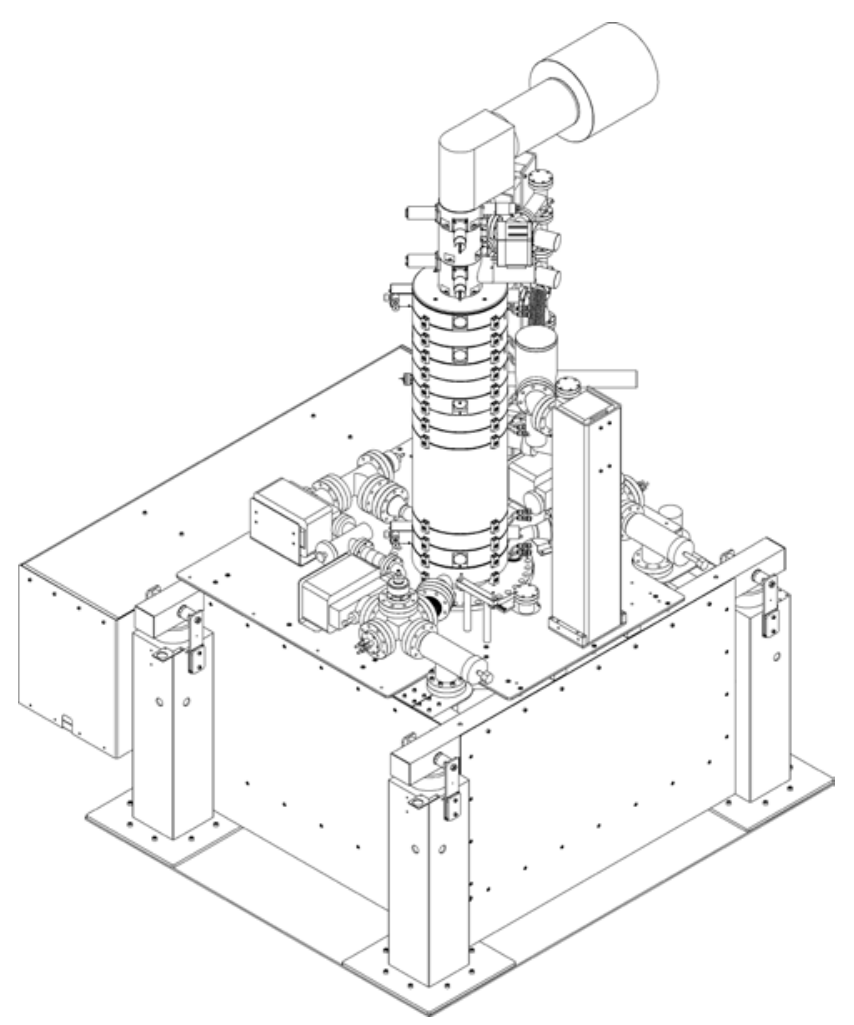

Fig. 1. Design drawing of the $200 \mathrm{kV}$ CFEG Nion UltraSTEM $^{\mathrm{TM}}$.

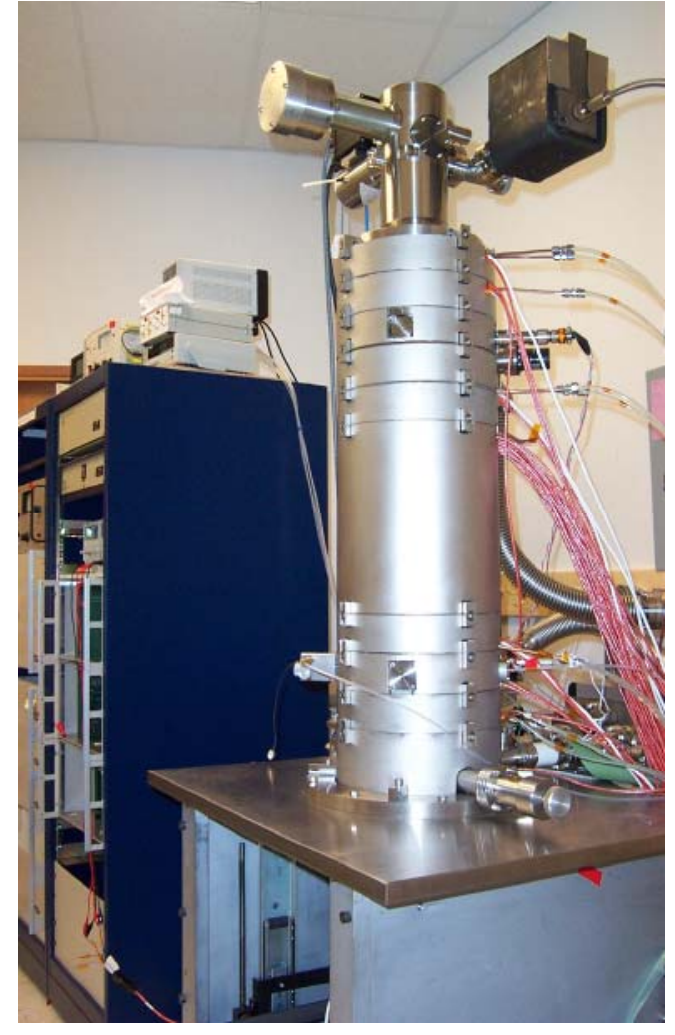

Fig. 2. The new column mounted on a $100 \mathrm{kV}$ VG gun. 